\title{
Identification of IngA, the structural gene of longus type IV pilus of enterotoxigenic Escherichia coli
}

\author{
Oscar G. Gómez-Duarte, ${ }^{1}$ Alejandro Ruiz-Tagle, ${ }^{2}$ Diana C. Gómez, ${ }^{1}$ \\ Gloria I. Viboud, ${ }^{3}$ Karen G. Jarvis, ${ }^{1}$ James B. Kaper ${ }^{1}$ and Jorge A. Girón ${ }^{2}$
}

Author for correspondence: Jorge A. Girón. Tel: +52 2233 2010. Fax: +52 22444518. e-mail: igiron@siu.buap.mx

1 Center for Vaccine Development, University of Maryland School of Medicine, 685 West Baltimore St, Baltimore, MD 21201, USA

2 Centro de Investigaciones en Ciencias Microbiológicas, Benemérita Universidad Autónoma de Puebla, Apartado Postal 1622, Puebla, Pue., Mexico

3 Instituto Nacional de Microbiología Dr. Carlos $\mathbf{G}$. Malbrán, Ave Vélez Sarsfields 563 CAP.C.P. 1,281, Buenos Aires, Argentina

\begin{abstract}
Human enterotoxigenic Escherichia coli (ETEC) produces a type IV pilus termed longus which is encoded on large plasmids in association with colonization factor antigens (CFAs) and enterotoxins. A plasmid-derived 7 kbp BamHI DNA fragment hybridizing with an oligonucleotide probe designed from the aminoterminal amino acid sequence of the denatured $22 \mathrm{kDa}$ structural longus pilin subunit was subcloned and sequenced. DNA sequencing analysis revealed an open reading frame, designated IngA, whose predicted amino acid sequence matched perfectly the $N$-terminal sequence of LngA obtained by Edman degradation. IngA is the first gene described of the longus gene cluster. Cloned IngA encoded and expressed a prepilin protein of 236 residues with a calculated mass of $25.17 \mathrm{kDa}$. The prepilin is apparently processed into a mature pilin of 206 residues with a calculated mass of $21.5 \mathrm{kDa}$. The predicted peptide sequence of IngA showed 78.8 and $37 \%$ identity to CFA/II pilin (CofA) of ETEC and the toxin-coregulated pilus (TCPA) of Vibrio cholerae. Peptide sequence homology between IngA and cofA was more prominent towards the amino terminus than within the carboxy region. Like other type IV pilins, LngA contains two cysteine residues towards the carboxy-terminal region. Transmission electron microscopy and immunoblot analysis of ETEC strains expressing either longus or CFA/III detected antigenic differences between native and denatured epitopes of these pili. In addition, differential regulation of pilus expression was identified when ETEC strains were grown in different media. Our data indicate that longus and CFA/III are two distinct but yet highly related type IV pili of ETEC.
\end{abstract}

Keywords: longus, type IV pili, colonization factor, enterotoxigenic, ETEC

\section{INTRODUCTION}

The ability of bacterial pathogens to colonize and cause disease is attributed in part to the expression of filamentous surface factors termed pili or fimbriae, that mediate adherence directly to the host cell receptor or indirectly as bridging ultrastructures (Brinton, 1965;

Abbreviations: Bfp, bundle-forming pilus; $C A B, C D C$ anaerobe blood; ETEC, enterotoxigenic Escherichia coli; CFA, colonization factor antigen; CS, coli surface antigen; LT, labile enterotoxin of ETEC; ST, stable enterotoxin of ETEC; Tcp, toxin-coregulated pilus; TSAB, trypticase soy agar + sheep blood.

The GenBank accession number for the sequence reported in this paper is AD004308.
Beachey, 1981). Bacterial adhesion is then the first step in the establishment of infections by pathogens that remain confined to the extracellular spaces or by invasive bacteria that mobilize into the cellular cytosol.

Pili have been classified on the basis of serology, morphology, biochemical features and receptor specificities (Klemm, 1985; Strom \& Lory, 1993). The type IV pilus family comprises pilins, which share structural and functional properties such as similarities at the $\mathrm{N}$ termini of their pilin structural subunits and a highly conserved $\mathrm{N}$-terminal domain of 25-30 amino acid residues. They possess a leader peptide sequence of variable length, which is important for processing of the precursor prepilin into mature pilin by a prepilin 
peptidase. The synthesis of functional pili requires the presence of several accessory genes which are involved in cleavage of the leader peptide, methylation of the newly formed $\mathrm{N}$-terminal methylphenylalanine, export across the cell envelope, and anchorage and assembly of subunits into the pilus organelle.

ETEC produces a watery diarrhoea which accounts for a high rate of infantile morbidity and mortality in developing countries (Levine, 1987; Levine et al. 1993). Colonization of intestinal mucosa by ETEC strains is mediated by a variety of surface fimbrial appendages called colonization factor antigens (CFAs), coli surface antigens (CSs) and putative colonization factors (Evans et al., 1978; McConnell, 1991; Levine et al., 1995). These surface structures have been identified after growth at $37^{\circ} \mathrm{C}$ on CFA agar as peritrichous pili $(1-5 \mu \mathrm{m}$ long) generally encoded on large plasmids in association with heat-stable (ST) and/or heat-labile (LT) enterotoxins which are responsible for the net secretion of electrolytes and water into the intestinal lumen (Evans et al., 1978; Klemm, 1985; Levine, 1987).

A considerable number of human ETEC serotypes produce, in addition to the well-known CFAs, a plasmidencoded type IV pilus termed longus (Girón et al., 1994). The $\mathrm{N}$ terminus of the major repeating subunit of longus (LngA) has an apparent molecular mass of $22 \mathrm{kDa}$ which shows significant $\mathrm{N}$-terminal amino acid sequence similarities to TcpA of Vibrio cholerae and BfpA of EPEC (Taylor et al., 1987; Girón et al., 1991, 1994). A survey of the prevalence of the longus pilin structural gene $\ln g A$ among ETEC showed that $\ln g A$ was found in ETEC producing other CFAs. CFA/II-producing ETEC had the highest level of association with longus, followed by CFA/I and CFA/IV. $\operatorname{lng} A$ was more often associated with ETEC strains that produce ST only than with strains that produce ST and LT or LT alone. Some ETEC strains lacking any known CFAs were also shown to contain $\operatorname{lng} A$ and to produce longus (Girón et al., 1995a).

Recently, DNA sequencing analysis of gene encoding $\mathrm{CFA} / \mathrm{III}$ (cofA) showed that this pilus belongs to the growing type IV pilus family (Taniguchi et al., 1995; Girón et al., 1997). In an effort to characterize the genetic determinants involved in longus biogenesis, we report here the cloning and DNA sequencing analysis of the structural gene of longus, $\operatorname{lng} A$. Molecular and immunological comparisons between longus and CFA/ III indicate that these pili share some structural type IV pilus features but also show differences at the DNA and protein level suggesting the close relatedness of these two determinants of ETEC.

\section{METHODS}

Bacterial strains, plasmids and growth conditions. ETEC and other strains generated in this study are listed in Table 1. ETEC E9034A (O8:H9) is a wild-type strain producing longus and CS3 (Girón et al., 1994) and was used as a positive control of longus production. ETEC E9034P strain is a plasmidless derivative of E9034A unable to produce longus and was used as a negative control. Other longus-producing ETEC have been reported earlier (Girón et al., 1994). ETEC E34420A $\left(\mathrm{O} 25: \mathrm{H}^{-}\right)$, also known as $31-10$, produces CFA/III, Z84-1 $\left(\mathrm{O} 25: \mathrm{H}^{-}\right)$also produces CFA/III, and E34420B is a plasmidless derivative of E34420A lacking CFA/III production (Knutton et al., 1989; McConnell \& Rowe, 1989). These strains were used as positive and negative controls of CFA/III production, respectively. pE9034A is a $90 \mathrm{kbp}$ virulence plasmid of wild-type ETEC E9034A that contains $\operatorname{lng} A$ and longus-related genes, in addition to CS3 and enterotoxin genes. pJAG1 is a pACYC177 plasmid carrying a $7 \mathrm{kbp}$ BamHI fragment obtained from pE9034A. pOG140 is a pBluescript SK plasmid carrying a $1 \mathrm{kbp}$ EcoRV insert containing the entire $\operatorname{lng} A$ gene. pOG 309 is a pBluescript SK plasmid carrying a $0.3 \mathrm{kbp}$ Pst I fragment containing the $3^{\prime}$ region of $\operatorname{lng} A$. pJAG11 is a pACYC177 plasmid carrying a $1 \mathrm{kbp} P s t \mathrm{I}$ fragment containing a truncated portion of $\operatorname{lng} A$. ETEC strains were maintained at $-70{ }^{\circ} \mathrm{C}$ in Luria broth and $15 \%(\mathrm{v} / \mathrm{v})$ glycerol, and were cultured on CFA agar $(1 \%$ Casamino acids, $0 \cdot 15 \%$ yeast extract, $0.005 \% \mathrm{MgSO}_{4}$, $0.0005 \% \mathrm{MnCl}_{2}, 2 \%$ agar; $\mathrm{pH} 7 \cdot 4$ ) for expression of CFAs (Evans et al., 1978). For expression of longus, CDC anaerobe blood ( $\mathrm{CAB}$ ) agar (BBL Microbiological Systems), and trypticase soy agar supplemented with $5 \%(\mathrm{v} / \mathrm{v})$ defibrinated sheep blood (TSAB) were used. Recombinant strains were grown on Luria agar or broth media with the appropriate antibiotics.

Sequencing of IngA and analysis. DNA sequencing of both DNA strands of $\ln g A$ was carried out using the Sequenase kit version 2 (US Biochemical). Plasmids pJAG1, pJAG11, pOG309 and pOG140 were used as DNA templates. Sequence analysis and homology studies were performed using the programs from the Genetics Computer Group (1991).

Molecular and genetic techniques. Restriction endonuclease digestion, ligation, transformation, plasmid DNA preparations and DNA electrophoresis were performed using standard techniques (Sambrook et al., 1982). Electroporation of plasmid DNA into recipient strains in $10 \%(\mathrm{v} / \mathrm{v})$ glycerol was performed in $0.2 \mathrm{~cm}$ cuvettes using a Gene Pulser (Bio Rad) set at 400 ohms and $2.5 \mathrm{kV}$.

SDSPAGE and immunoblotting of whole-cell extracts. To prepare whole-cell extracts, approximately $1 \times 10^{8}$ bacterial c.f.u. were harvested from agar plates (TSAB, CAB, or CFA media), resuspended in $50 \mathrm{mM}$ PBS $\mathrm{pH} 7 \cdot 4$, and boiled for $5 \mathrm{~min}$ in SDS-PAGE sample buffer (Laemmli, 1970). After electrophoresis through $16 \%$ polyacrylamide gels, proteins were transferred onto nitrocellulose membranes and analysed by Western blotting using a 1:2000 dilution of rabbit antiCFA/III antiserum or rabbit anti-longus antiserum. Secondary alkaline-phosphatase-conjugated $\operatorname{IgG}$ antibodies were used at 1:2000 dilution. The blots were developed with a mixture of nitro blue tetrazolium and 5-bromo-4-chloro-3-indolyl phosphate (Sigma).

Electron microscopy. For structural and immuno-electron microscopy studies, bacteria were negatively stained with $1 \%$ phosphotungstic acid, $\mathrm{pH} 7 \cdot 4$ and examined in a JEOL JEM 1200 EX II transmission electron microscope at $80 \mathrm{kV}$ as described previously (Girón et al., 1994, 1995b). For immunological analysis of longus- or CFA/III-expressing ETEC strains, bacteria were reacted with rabbit anti-longus antiserum and/or mouse monoclonal anti-CFA/III 3:3 antibody diluted 1:100 in PBS containing 1\% BSA (Sigma) for $30 \mathrm{~min}$ on Formvar-coated copper grids. The grids were washed three 
Table 1. List of strains used or generated in this study

\begin{tabular}{|c|c|c|}
\hline Strain/plasmid & Description & Reference \\
\hline ETEC E9034A & $\mathrm{O} 8: \mathrm{H} 9$, longus and $\mathrm{CS} 3$ & Girón et al. (1994) \\
\hline ETEC E9034P & $\begin{array}{l}\text { Plasmidless derivative of E9034A lacking } \\
\text { longus production }\end{array}$ & $\mathrm{CVD}^{*}$ collection \\
\hline ETEC B2C & O6: $\mathrm{H} 16$, longus, CS1 and CS3 & Girón et al. (1994) \\
\hline $\begin{array}{l}\text { ETEC E34420A } \\
(31-10)\end{array}$ & $\mathrm{O} 25: \mathrm{H}^{-}, \mathrm{CFA} / \mathrm{III}$ and CS6 & Viboud et al. (1993) \\
\hline ETEC E.34420B & $\begin{array}{l}\text { Plasmidless derivative of E34420A lacking } \\
\text { CFA/III production }\end{array}$ & Viboud et al. (1993) \\
\hline ETEC Z84-1 & $\mathrm{O} 25: \mathrm{H}^{-}, \mathrm{CFA} / \mathrm{III}$ & Viboud et al. (1993) \\
\hline E. coli $\mathrm{DH} 5 \alpha$ & $\begin{array}{l}\text { supE33DlacU169 (080 lacZ } \Delta \mathrm{M} 15) \text { hsdR17 } \\
\text { recA1 endA1 gyrA96 thi-1 relA1 }\end{array}$ & BRL \\
\hline pBluescriptSKII - & Cloning vector $\left(A p^{r}\right)$ & Stratagene \\
\hline pJAG1 & $\begin{array}{l}7.0 \mathrm{kbp} \mathrm{Bam} \mathrm{HI} \mathrm{fragment} \mathrm{containing} \mathrm{longus} \\
\text { genes cloned into pACYC177 }\end{array}$ & Girón et al. (1994) \\
\hline pJAG11 & $\begin{array}{l}\text { pACYC177 with a } 1.0 \mathrm{kbp} P s t \mathrm{I} \text { insert with a } 5^{\prime} \\
\text { region of the } \operatorname{lng} A \text { gene }\end{array}$ & This study \\
\hline pOG140 & $\begin{array}{l}\text { pBluescript SKII with a } 1.0 \mathrm{kbp} E c o \mathrm{RV} \text { insert } \\
\text { of the entire } \operatorname{lng} A \text { gene }\end{array}$ & This study \\
\hline pOG309 & $\begin{array}{l}\text { pBluescript SKII with a } 0.3 \mathrm{kbp} P \text { stI insert } \\
\text { with the } 3^{\prime} \text { region of } \operatorname{lng} A\end{array}$ & This study \\
\hline
\end{tabular}

* Center for Vaccine Development, Baltimore, MD.

times with PBS containing $1 \%$ BSA and reacted with a $1: 10$ dilution of anti-rabbit and/or anti-mouse IgG conjugated to 10 or $5 \mathrm{~nm}$ gold particles (Amersham), respectively. The bacteria were stained and observed by electron microscopy as before.

ELISA. Production of longus or CFA/III was evaluated by ELISA after bacterial growth in different culture media. Briefly, longus-producing bacteria were grown on TSAB and CFA/III-producing bacteria were grown on CFA agar. Both strains were incubated overnight at $37^{\circ} \mathrm{C}$. E9034P and E34420B were used as negative controls for longus and CFA/III production, respectively. Bacterial suspensions were prepared in carbonate buffer $\mathrm{pH} 9.6$ and adjusted to the same concentration until reaching an $\mathrm{OD}_{600}$ of 1.0 . Microtitre plates (NUNC) were coated overnight at $4^{\circ} \mathrm{C}$ in quadruplicate with $100 \mu$ l bacterial suspension, after which unbound bacteria were removed by washing with PBS containing $0.5 \%$ Tween 20 (PBST). The wells were blocked with $1 \%$ dry milk in PBST for $1 \mathrm{~h}$ at $37^{\circ} \mathrm{C}$, washed and then incubated with primary antibodies (rabbit anti-longus or rabbit anti-CFA/III) for $1 \mathrm{~h}$ at room temperature. After washing, secondary antibodies conjugated to alkaline phosphatase were added for $1 \mathrm{~h}$ at room temperature. Reactivity was measured by adding the appropriate substrate and read in an ELISA reader at $405 \mathrm{~nm}$.

\section{RESULTS}

\section{Analysis of IngA nucleotide sequence}

ETEC expressing longus was shown to hybridize with an oligonucleotide probe specific for $\operatorname{lng} A$ (Girón $e t$ al., 1994). A $7 \mathrm{kbp} \mathrm{BamHI}$ fragment that hybridized with this probe in Southern blots was cloned from the large plasmid of ETEC E9034A into pACYC177 to generate
pJAG1. This plasmid and additional subclones (pJAG11, pOG140 and pOG309) generated in the present study were used to sequence the gene encoding the pilin subunit of longus. Approximately $1 \mathrm{kbp}$ of DNA was sequenced from pJAG1 and a 708 bp ORF designated $\ln g A$ was found to encode a predicted protein of 236 residues. The predicted mature product of $\operatorname{lng} A$ contains 206 amino acids, with a calculated molecular mass of $21.51 \mathrm{kDa}$, which is in agreement with the estimated mass of $22 \mathrm{kDa}$ of LngA obtained by electrophoresis and Western blot analysis. The CFA/III, TCP (Rhine \& Taylor, 1994) and BFP (Donnenberg et al., 1992; Stone et al., 1996) mature type IV pilins contain 208, 199 and 180 amino acid residues, respectively. A search through the GenBank database confirmed the sequence similarities between LngA and type IV pili. In addition, the predicted sequence of the mature pilin was identical to the $\mathrm{N}$-terminal amino acid sequence (20 residues) previously obtained from the $22 \mathrm{kDa}$ principal subunit of longus (Girón $e t$ al., 1994) further confirming that $\operatorname{lng} A$ is the structural subunit gene of longus.

A consensus Shine-Dalgarno sequence was found $7 \mathrm{bp}$ upstream of the ATG initiation codon (data not shown). No typical promoter sequences were found upstream of the $\ln g A$ gene, suggesting that $\ln g A$ may be part of an operon with a promoter located further upstream. The prepilin protein may require processing by a prepilin peptidase to produce a mature pilin, as is the case with other type IV pilins. LngA contains a highly basic hydrophilic amino acid leader sequence and a highly hydrophobic $\mathrm{N}$-terminal domain typical of the type IV 


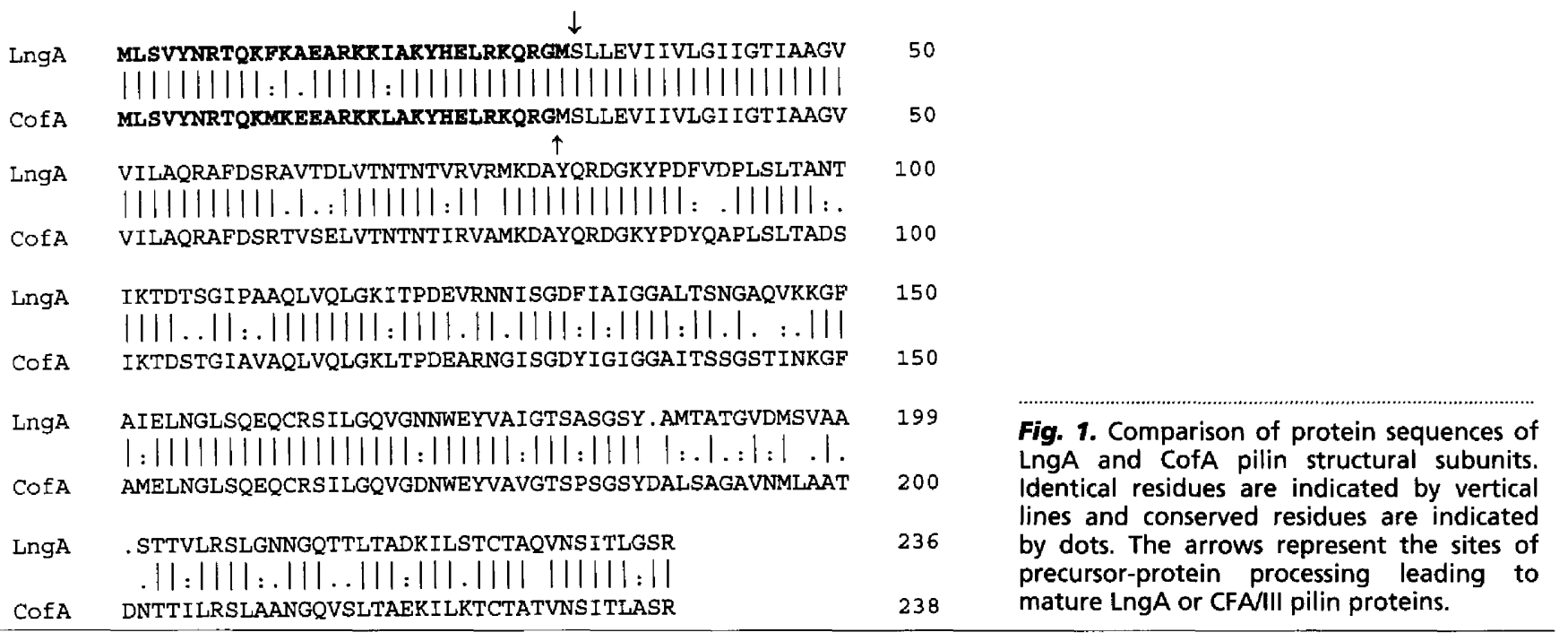

pilins (Fig. 1). While the signal peptide of class A type IV pilins is short (8-13 residues), the leader sequences of longus and CFA/III precursor are 30 residues long. TcpA and BfpA have a leader sequence of 26 and 13 residues, respectively. The Ser-Leu-Leu-Glu-Val peptide sequence found immediately after the predicted processing site of LngA is highly homologous to the consensus sequence Thr-Leu-Ile-Glu-Leu found in proteins processed by the prepilin peptidase of Pseudomonas aeruginosa and other members of the type IV pilus family. Previously, the $\mathrm{N}$-terminal amino acid sequencing analysis of the denatured LngA showed that its first residue is a serine, indicating that the signal peptide should cleave after Met-30 (Girón et al., 1994). In contrast, Taniguchi et al. (1995) noted that the signal peptide in CofA is cleaved between Gly-29 and Met-30. Similar to CofA, TcpA and BfpA, LngA contains two cysteines present at the $\mathrm{C}$-terminal end.

LngA shows $\sim 79 \%$ identity to CofA and $\sim 37 \%$ identity to TcpA (from both O1 and O139 V. cholerae). Lower similarity is seen between LngA and BfpA. Higher homology between LngA and Cof A is seen at the Nterminus of the peptides (Fig. 1). Only three conserved changes are present at the signal peptide. At the Cterminus, instead, higher diversity is observed, particularly after residue 140 . It is in this area where two residues present in CofA are absent in LngA.

At the DNA level, the $\operatorname{lng} A$ and cof $A$ genes are $74.2 \%$ identical (data not shown) with higher homology towards the $5^{\prime}$ ends of the genes. There is also significant homology between $\operatorname{lng} A$ and Erwinia chrysanthemi outC (secretory component); Eikenella corrodens type IV N terminal methyl phenylalanine-pilin and Xanthomonas campestris pef (data not shown). These sequence similarities are concentrated at the $5^{\prime}$ ends of these genes and less significant amino acid sequence homologies are observed between the carboxy regions of longus and other type IV pili. This is consistent with previous observations with various type IV pili (Girón et al.,

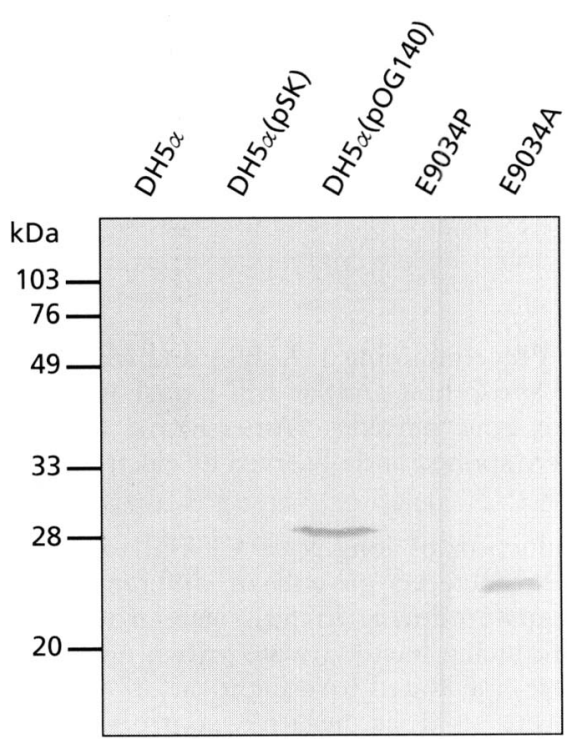

Fig. 2. Analysis of recombinant LngA protein expression. Whole-cell lysates of recombinant $\mathrm{DH} 5 \alpha$ and ETEC strains were reacted with anti-longus antiserum by immunoblotting. Wildtype ETEC strain E9034A was used as a positive control of mature LngA ( $22 \mathrm{kDa}$ ) expression. DH5 $\alpha$ and $\mathrm{DH} 5 \alpha(\mathrm{pSK}) \mathrm{E}$. coli strains and the plasmidless E9034P were used as negative controls. $\mathrm{DH} 5 \alpha$ (pOG 140) harbours the entire IngA gene in pBluescript SK and expresses a 25 kDa prepilin peptide.

1994; Strom \& Lory, 1993; Taniguchi et al., 1995; Taylor et al., 1987).

\section{Expression of recombinant LngA protein}

To confirm that the cloned $\operatorname{lng} A$ gene encodes the structural subunit of longus pilus, a whole cell lysate of Escherichia coli DH5 $\alpha$ (pOG140) carrying the lngA gene was evaluated by immunoblotting using the anti-longus rabbit antisera as primary antibody. As shown in Fig. 2, 
two proteins of the same intensity were observed. A $25 \mathrm{kDa}$ protein was observed in the lane containing the DH5 $\alpha$ (pOG140) recombinant strain. The molecular mass of this protein correlates well with the predicted molecular mass of $25 \cdot 1 \mathrm{kDa}$ for the LngA prepilin protein. The second protein of $22 \mathrm{kDa}$ was observed in the lane containing the wild-type ETEC E9034A strain that was used as a positive control for expression of the mature LngA pilin. This analysis demonstrates that the sequenced $\ln g A$ gene cloned in $\mathrm{DH} 5 \alpha$ expresses the prepilin LngA protein. Absence of specific prepilin peptidase and fimbrial biogenesis genes in $\mathrm{DH} 5 \alpha$ renders the LngA protein unable to be modified into the mature $22 \mathrm{kDa}$ pilin protein.

\section{Antigenic relatedness between longus and CFA/III pili}

In view of the DNA and protein similarities observed between CFA/III and longus, antigenic cross-reactivities were examined by immunoblotting using specific antiCFA/III and anti-longus antibodies. Towards this aim, six CFA $/ \mathrm{III}^{+}$ETEC strains (Honda et al., 1984; Shinagawa et al., 1993; Viboud et al., 1993) and six longus ${ }^{+}$ETEC strains (Girón et al., 1994) were grown on TSAB agar and examined by immunoblotting (Fig. 3). Rabbit polyclonal anti-longus antibodies reacted strongly with longus ${ }^{+}$strains and weakly with $\mathrm{CFA} / \mathrm{III}^{+}$ strains (Fig. 3a). In contrast, rabbit anti-CFA/III antiserum showed a strong reaction with CFA/III pilin and no reactivity with LngA (Fig. 3b). LngA was detected after bacterial growth on TSAB (Fig. 3) or CAB agar, but not on CFA agar. In contrast, CFA/III was readily expressed after bacteria were grown on CFA, TSAB, or $\mathrm{CAB}$ media. While the CFA/III pilin was quite homogeneous in size, LngA showed more size variability (22-24 kDa) (data not shown). The sequence homology and the immunological cross-reactivities support the existence of common epitopes between CFA/III and longus exposed after denaturation (Girón et al., 1997).

\section{Immunogold labelling of longus and CFA/III}

To further confirm the presence of cross-reacting native epitopes between longus and CFA/III pili, immunogold electron microscopy was performed on ETEC strains. Longus filaments were recognized by anti-longus antibodies (Fig. 4a) and CFA/III pili were specifically immunogold labelled with monoclonal anti-CFA/III 3:3 antibodies (Fig. 4c). Longus, however, was not labelled with anti-CFA/III monoclonal and CFA/III was not labelled with anti-longus antibodies (data not shown). To explore the possibility that both pili could be expressed at the same time by either group of bacteria, simultaneous gold labelling with monoclonal (anti$\mathrm{CFA} / \mathrm{III}$ ) and rabbit (anti-longus) antibodies was performed using species-specific IgG conjugates coupled to $5 \mathrm{~nm}$ (anti-mouse) or $10 \mathrm{~nm}$ (anti-rabbit) gold conjugates. CFA/III + strains were labelled only with antiCFA/III antibodies (Fig. 4b) and longus ${ }^{+}$strains were labelled only with anti-longus antibodies (data not shown). Thus, it is apparent that CFA/III and longus are
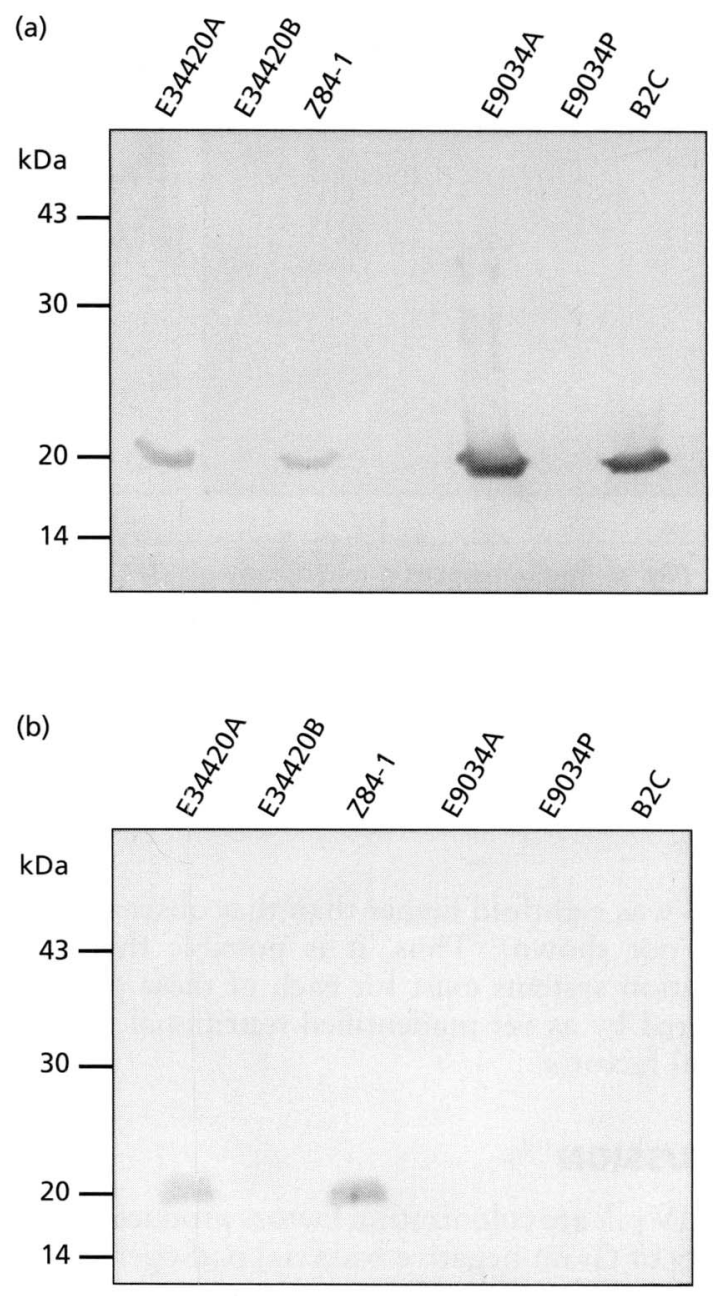

Fig. 3. Analysis of immune cross-reaction between LngA and CofA. ETEC strains were grown on TSAB agar and analysed by Western blotting using rabbit anti-longus antiserum (a) and rabbit anti-CFA/III antiserum (b). E34420A and Z84-1 are CFA/III strains while E34420B is the CFAVIII-negative control; E9034A and $\mathrm{B} 2 \mathrm{C}$ are longus ${ }^{+}$strains while E9034P is a longus-negative control. Note the lack of reactivity between longus and antiCFA/II antibodies.

not produced simultaneously by a particular ETEC strain and that no apparent cross-reactivity occurs between longus and CFA/III native epitopes. Negative controls, E9034P and E3442OB, did not show gold labelling with either antiserum (data not shown).

\section{Differential pilus expression}

To learn about the level of pilus expression on different growth media by E34420A and E9034A, an ELISA was performed using rabbit polyclonal anti-longus or antiCFA/III sera. Since the antibodies employed are specific for each pilus type, the degree of absorbance was considered as a parameter of pilus production on each of the media tested. It appears that E34420A produces $\sim 40 \%$ more CFA/III on CFA agar than on TSAB agar. In contrast, the level of longus expression by E9034A on 

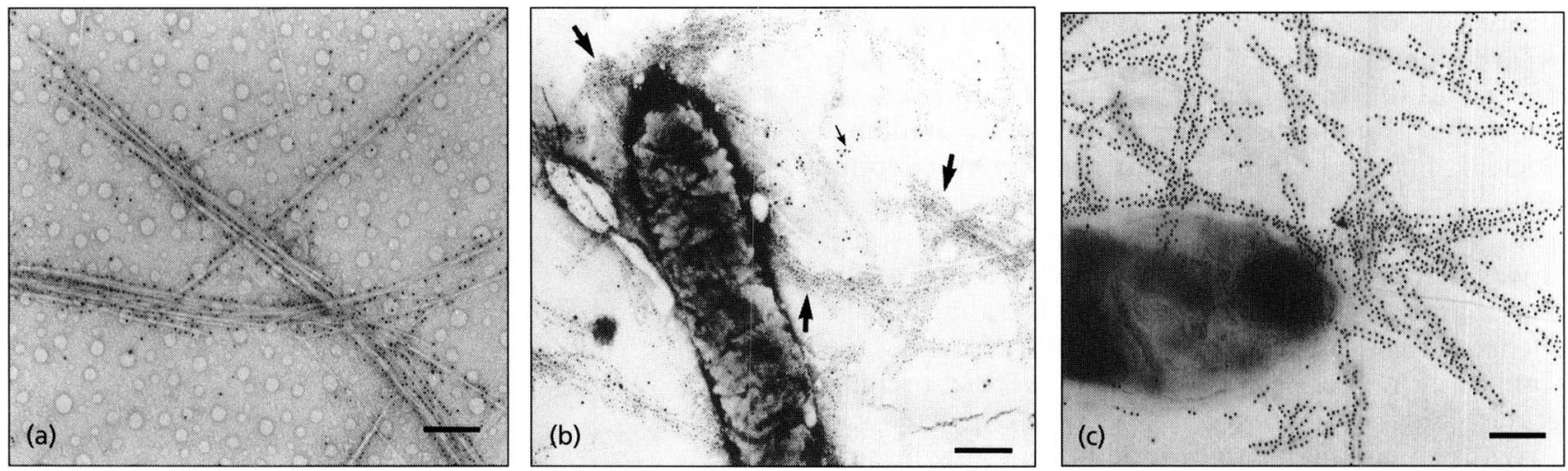

Fig. 4. Immunoelectron microscopy of ETEC strains producing longus or CFA/II pili. (a) Purified longus pili produced by E9034A on CAB agar and reacted with anti-longus antibodies. Bar, $0.3 \mu \mathrm{m}$. (b) Dual labelling of E34420A (CFA/II') with rabbit anti-longus and mouse monoclonal anti-CFAlll 3:3, followed by anti-rabbit IgG conjugated with $10 \mathrm{~nm}$ gold particles and anti-mouse IgG conjugated with $5 \mathrm{~nm}$ gold particles. Note that only CFAIII antibodies bind to the pili (large arrows). Small arrows point at background $10 \mathrm{~nm}$ gold particles not binding to pili. Bar, $0.175 \mu \mathrm{m}$. (c) E34420A producing peritrichous CFAlII pili reacted with monoclonal anti-CFA/II $3: 3$ and anti-mouse IgG conjugated to $10 \mathrm{~nm}$ gold particles. Bar, $0.175 \mu \mathrm{m}$.

TSAB was eightfold higher than that observed on CFA (data not shown). Thus, it is possible that different regulation systems exist for each of these pili that are triggered by as yet unidentified nutritional or environmental factor(s).

\section{DISCUSSION}

Type IV pili are colonization factors produced by a wide variety of Gram-negative bacterial pathogens including some enterobacteria (Strom \& Lory, 1993; Weir \& Maars, 1992; Maars, 1994). V. cholerae produces a TCP (Taylor et al., 1987), EPEC produces BFP (Girón et al., 1991) and ETEC produces longus and CFA/III (Girón et al., 1994; Taniguchi et al., 1995), all of which show high $\mathrm{N}$-terminal amino acid sequence similarities (Girón et al., 1997). Among these, longus and CFA/III are the least well characterized in terms of the genetic organization and regulation of gene expression. Recent DNA sequencing and expression analysis of an $\sim 10 \mathrm{kbp} b f p$ gene cluster carried on a large plasmid of EPEC showed that 14 consecutive genes located in tandem are required for expression of native BFP (Sohel et al., 1996; Stone et al., 1996). Taniguchi et al. (1995) reported that a $17.5 \mathrm{kbp}$ fragment obtained from an ETEC strain directed the synthesis of CFA/III pili in an E. coli laboratory strain. These workers showed that the Nterminal region of LngA is identical to that of CofA, suggesting that these pili might be one pilus type produced by ETEC.

In this study, we report the nucleotide sequence of the structural gene of longus $\operatorname{lng} A$, and show that the recombinant $\operatorname{lng} A$ gene expresses a $25 \mathrm{kDa}$ LngA prepilin protein that is specifically recognized by antilongus antiserum. The antigenic similarity between longus and CFA/III was analysed to elucidate the relatedness of these two type IV pili of ETEC. Analysis of the $\ln g A$ DNA sequence reveals that the predicted peptide sequence is $\sim 79 \%$ identical to CofA and $\sim 37 \%$ identical to TcpA and that the sequence similarities are concentrated at the $\mathrm{N}$-terminal regions of the proteins. Another common characteristic with CofA and other type IV pili is the presence of two cysteine residues at the C-terminus. It has been proposed that these amino acids contribute to disulphide bond formation, which could be important for secretion of the mature pilus protein across the outer membrane (Taniguchi et al., 1995). It then appears that within ETEC, genetic divergences have occurred yielding type IV pilus proteins with similar biochemical and genetic (and probably functional) characteristics that nevertheless show distinct regulatory features.

CFA/III is a semiflexible $(6-10 \mu \mathrm{m}$ long) pilus found in ETEC O25:H16 and $\mathrm{O} 25: \mathrm{H}^{-}$producing LT only, while longus ( $>20 \mu \mathrm{m}$ long) appears to be widely distributed among heterologous ETEC serotypes, mainly those producing ST (Girón et al., 1995a). CFA/IIl pili are composed of a $20.5 \mathrm{kDa}$ repeating subunit (Shinagawa et al., 1993) while longus is composed of a major structural subunit of $22-24 \mathrm{kDa}$ (Girón et al., 1994). The predicted molecular mass of LngA described here correlates well with the mass determined by SDS-PAGE. In our hands, the size of CofA and LngA was almost indistinguishable on immunoblots. We examined the effect of the growth media on expression of longus or CFA/III by ELISA. ETEC E34420A expresses favourably CFA/III on TSAB and CFA agar while longus is better expressed on TSAB agar. Interestingly, longus is not produced in modified Eagle's medium (DMEM, Difco), a condition that promotes BFP expression by EPEC. The fact that expression of longus requires more defined growth media conditions suggests that CFA/III and longus pili are under the control of different regulatory elements. Further studies on the regulation of longus 
gene expression will be necessary to elucidate the nature of these regulatory elements.

We tested cross-reactivities between longus and CFA/III by immunoelectron microscopy. Anti-longus antibodies did not bind to peritrichous or cell-free CFA/III pili. Similarly, a monoclonal anti-CFA/III antibody did not label longus on prototype longus strains. The lack of recognition of CFA/III by polyclonal anti-longus antibody suggests the absence of common native epitopes on these two pili. There is, however, antigenic relatedness between these two ElFC pili when examined in immunoblots. Anti-longus antibodies recognized both longus and $C F A / I I I$ pilin subunits, suggesting the presence of common epitopes exposed after denaturation. Rabbit anti-CFA/III antiserum, however, did not react with LngA. CFA/III pilins produced by CFA $/ \mathrm{III}^{+}$strains appeared to be rather homogeneous in size while longus pilins showed more heterogeneity as determined by immunoblotting of longus ${ }^{+}$strains. Similar size and antigenicity differences were observed among BfpA produced by EPEC, employing polyclonal and monoclonal anti-BFP antibodies (Girón et al. 1993a, 1995c). Thus, it appears that within a bacterial species or a category of pathogens such as FPEC or FTHC, a subfamily of related pilins might be produced.

Most type IV pili contribute to virulence by promoting attachment to various types of receptors during colonization of host mucosal surfaces (Strom \& Lory, 1993). For example, CFA/III pili mediate adherence to intestinal epithelial cells of infant rabbits, Caco-2 cells and human enterocytes (Knutton et al., 1989). However, neither CFA/III nor longus-producing FTEC haemagglutinates human red blood cells (Girón et al., 1994; Honda et al., 1984). The TCP was shown to be an important colonization factor in the pathogenesis of cholera (Taylor et al., 1987). The demonstration of BFP within bacterial clusters adhering to HEp-2 cells and the inability of $b f p A$ mutants to form localized adherence suggests that BFP is the EPEC adherence factor (Girón et al., 1993a, b). With respect to longus, more genetic and functional studies are needed to elucidate the role of longus as a colonization factor. Nevertheless, an $E$. coli $\mathrm{K}-12$ strain harbouring plasmid pJAG1, which contains a $7 \mathrm{kbp}$ fragment encoding $\operatorname{lng} A$, became highly aggregative after growth in liquid broth. In summary, distinction between longus and CFA/III pili can be made on the bases of morphological features, serotype distribution and association with enterotoxin genes. Our data on non-cross-reactivity at native epitopes and on differential regulation of pili expression further confirm the differences between these pili, cven though $\operatorname{lng} A$ and $\operatorname{cof} A$ genes were found to be highly similar at the DNA and protein levels. Thus, it appears that longus and CFA/III are two independent type IV pili of ETEC. Due to the significant homology between longus and CFA/III pili, new genetic tools may be necessary to reevaluate the prevalence of these pili among ETEC. strains. Development of genetic tools, such as DNA probes, will be based on the analysis of DNA sequencing of $\operatorname{lng} A$ and $\operatorname{cof} A$ from multiple ETEC strains. Fur- thermore, genetic studies will be required to elucidare the common ancestor of these pilin genes and the stage in evolution where they began to diversify.

\section{ACKNOWLEDGEMENTS}

This work was supported by NIH 1 Grant No. Al21657 to J.B.K. and Conacyt Grant 3485P-M9607 to J.A. G. Special thanks to Stuart Knutton for ETEC 31-10, Karen Taylor for bacterial cultures and Timothy McDanicl for critical discussions.

\section{REFERENCES}

Beachey, E. H. (1981). Bacterial adherence: adhesin-receptor interactions mediating the attachment of bacteria to mucosal surfaces. Rev' Infect Dis 143, 325-343.

Brinton, C. C. (1965). The structure, function, synthesis, and genetic control of bacterial pili and a molecular model for DNA and R.VA transport in gram negative bacteria. J Trans $N$ Y Acad Sci 27, 100310.54

Donnenberg, M. S., Girón, J. A., Nataro, J. P. \& Kaper, J. B. (1992). A plasmid-encoded type IV fimbrial gene of enteropathogenic Escherichia coll associated with localized adherence. Mol Microbiol 22, 3427-3437.

Evans, D. G., Evans, D. J., Jr, Tjoa, W. S. \& Dupont, H. L. (1978). Detection and characterization of a colonization factor of enterotoxigenic Escherichia coli isolated from adults with diarrhea. Infect Immun 19, 727-736.

Genetics Computer Group (1991). Program Manual for the GCG package, 7 th edn. Madison, WI: University of Wisconsin.

Girón, J. A., Ho, A. S. Y. \& Schoolnik, G. K. (1991). An inducible bundle-forming pilus of enteropathogenic Fscherichia coli. Science 254, 710-713.

Girón, J. A., Ho, A. S. Y. \& Schoolnik, G. K. (1993a). (.haracterization of fimbriae produced by enteropathogenic Escherichia coli. J Bacteriol 175, 7391-7403.

Girón, J. A., Donnenberg, M. S., Martin, W. C., Jarvis, K. G. \& Kaper, J.B. (1993b). Distribution of the bundle-forming pilus structural gene (bfpA) among cnteropathogenic Escherichia coli (EPEC). J Infect Dis 168, 1037-1041.

Girón, J. A., Levine, M. M. \& Kaper, J. B. (1994). Longus: a long pilus ultrastructure produced by human enterotoxigenic Escherichia coli. Mol Microbiol 12, 71-82.

Girón, J. A., Viboud, G. I., Sperandio, V., Gómez-Duarte, O. G., Maneval, D., Albert, M. J., Levine, M. M. \& Kaper, J. B. (1995a). Prevalence and association of longus pilus structural gene ( $\operatorname{lng} A$ ) with colonization factor antigens, ST/LT enterotoxin types, and scrotypes of entcrotoxigenic Escherichia coli. Infect Immun 63, 4195-4198.

Girón, J. A., Xu, J.-G., González-Bonilla, C., Hone, D., Kaper, J. B. \& Levine, M. M. (1995b). Simultaneous expression of (FA/I and CS3 colonization factor antigens of enterotoxigenic Escherichia coli by aroC, aroD Salmonella typhi vaccine strain CVD908. Vaccine 13, 939-946.

Girón, J. A., Qadri, F., Azim, T., Jarvis, K., Kaper, J. B. \& Albert, M.J. (1995c). Monoclonal antibodies specific for the bundleforming pilus of enteropathogenic Escherichia coli. Infect Immun 63, 4949-4952.

Girón, J. A., Gómez-Duarte, O. G., Jarvis, K. G. \& Kaper, J. B. (1997). Longus pilus of enterotoxigenic Fscherichia coli and its relatedness to other rype 4 pili-a mini review. Gene 192, 39 4. 4. 
Honda, T., Arita, M. \& Miwatani, T. (1984). Characterization of new hydrophobic pili of human enterotoxigenic Escherichia coli: a possible new colonization factor. Infect Immun 43, 959-965.

Klemm, P. (1985). Fimbrial adhesins of Escherichia coli. Rev Infect Dis 7, 321-340.

Knutton, S., McConnell, M. M., Rowe, B. \& McNeish, A. S. (1989). Adhesion and ultrastructural properties of human enterotoxigenic Escherichia coli producing colonization factor antigens III and IV. Infect Immun 57, 3364-3371.

Laemmli, U. K. (1970). Cleavage of structural proteins during the assembly of the head of bacteriophage T4. Nature 227, 680-685.

Levine, M. M. (1987). Escherichia coli that cause diarrhea: enterotoxigenic, enteropathogenic, enteroinvasive, enterohemorrhagic, and enteroadherent. J Infect Dis 155, 377-389.

Levine, M. M., Ferreccio, C., Prado, V. \& 12 other authors (1993). Epidemiologic studies of Escherichia coli diarrheal infections in a low socioeconomic level periurban community in Santiago, Chile. Am J Epidemiol 138, 849-869.

Levine, M. M., Girón, J. A. \& Noriega, F. (1995). Fimbrial vaccines. In Fimbriae: Adhesion, Biogenics, Genetics and Vaccines, pp. 255-270. Edited by P. Klemm. Boca Raton, FL: CRC Press.

Maars, C. (1994). Type 4 pili in the families Moraxellaceae and Neisseriaceae. In Molecular Genetics of Bacterial Patbogenesis, pp. 127-143. Edited by V. L. Miller, J. B. Kaper, D. A. Portnoy \& R. R. Isberg. Washington, DC: American Society for Microbiology.

McConnell, M. M. (1991). Newly characterized putative colonization factors of human enterotoxigenic Escherichia coli. In Molecular Pathogenesis of Gastrointestinal Infections, pp. 79-85. Edited by T. Wädstrom. New York: Plenum.

McConnell, M. M. \& Rowe, B. (1989). Prevalence of the putative colonization factors CFA/III and PCFO159:H4 in enterotoxigenic Escherichia coli. J Infect Dis 159, 582-586.

Rhine, J. A. \& Taylor, R. K. (1994). TcpA pilin sequences and colonization requirements for $\mathrm{O} 1$ and $\mathrm{O} 139$ Vibrio cholerae. Mol Microbiol 13, 1013-1020.
Sambrook, J., Fritsch, E. F. \& Maniatis, T. (1982). Molecular Cloning: a Laboratory Manual. Cold Spring Harbor, NY: Cold Spring Harbor Laboratory.

Shinagawa, H., Taniguchi, T., Yamaguchi, O., Yamamoto, K. \& Honda, T. (1993). Cloning of the genes that control formation of the fimbrial colonization factor antigen III (CFA/III) from an enterotoxigenic Escherichia coli. Microbiol Immunol 37, 689-694.

Sohel, I., Puente, J. L., Ramer, S. W., Bieber, D., Wu, C.-Y. \& Schoolnik, G. K. (1996). Enteropathogenic Escherichia coli: identification of a gene cluster coding for bundle-forming pilus morphogenesis. J Bacteriol 178, 2613-2628.

Stone, K. D., Zhang, H.-Z., Carlson, L. K. \& Donnenberg, M. S. (1996). A cluster of fourteen genes from enteropathogenic Escherichia coli is sufficient for the biogenesis of a type IV pilus. Mol Microbiol 20, 325-337.

Strom, M. S. \& Lory, S. (1993). Structure-function and biogenesis of the type IV pili. Annu Rev Microbiol 47, 565-596.

Taniguchi, T., Fujino, Y., Yamamoto, K., Miwatani, T. \& Honda, T. (1995). Sequencing of the gene encoding the major pilin of pilus colonization factor antigen III (CFA/III) of human enterotoxigenic Escherichia coli and evidence that CFA/III is related to type IV pili. Infect Immun 63, 724-728.

Taylor, R. K., Miller, V. L., Furlong, D. B. \& Mekalanos, J. J. (1987). Use of $p h o A$ gene fusions to identify a pilus colonization factor coordinately regulated with cholera toxin. Proc Natl Acad Sci USA 84, 2833-2837.

Viboud, G. I., Binsztein, N. \& Svennerholm, A. M. (1993). Characterization of monoclonal antibodies against putative colonization factors of enterotoxigenic Escherichia coli and their use in an epidemiological study. J Clin Microbiol 31, 558-564.

Weir, S. \& Maars, C. F. (1992). Identification of type 4 pili in Kingella denitrificans. Infect Immun 60, 3437-3441.

Received 28 August 1998; revised 5 January 1999; accepted 19 March 1999. 